SOCIAL RESEARCH REPORTS

ISSN: 2066-6861 (print), ISSN: 2067-5941 (electronic)

\title{
COUPLES FACING THE AUTISM SPECTRUM DISORDER CHALLENGE: A LITERATURE REVIEW CONCERNING EMOTIONALLY FOCUSED THERAPY EFFECTIVENESS
}

Dalia STOIA, Mona VINTILA, Mihaela MINULESCU

Social Research Reports, 2019, Vol. 11, Issue 1, pp. 54-64

The online version of this article can be found at: www. researchreports.ro

\section{https://doi.org/10.33788/srr11.1.4}

Published by:

Expert Projects Publishing House

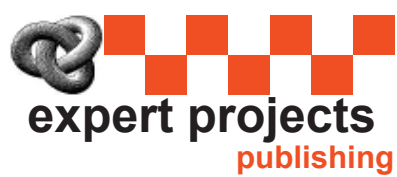

Covered by Index Copernicus International www.indexcopernicus.com

Directory of Open Access Journals www.doaj.org

On behalf of:

Center for Program and Social Development

Aditional services and information about Social Research Reports can be found at:

www.researchreports.ro 


\title{
COUPLES FACING THE AUTISM SPECTRUM DISORDER CHALLENGE: A LITERATURE REVIEW CONCERNING EMOTIONALLY FOCUSED THERAPY EFFECTIVENESS
}

\author{
Dalia STOIA ${ }^{1}$, Mona VINTILA², Mihaela MINULESCU³
}

\begin{abstract}
Recent surveys reinforce the fact that Autism Spectrum Disorder (ASD) is on the rise. In these cases, the family faces a chronic condition which etiology and means of treatment are still debated. The impact of the new reality is well known in the literature as a considerable increase in marital distress. Hence, until recently all the concern was around the therapy of the child. The comprehension of the psychological impact faced by the couple lead to a new approach addressing an integrative treatment plan in the case of ASD. In the new light, couple therapy is considered valuable in order to higher the family quality of life. The present literature review offers an overview of research exploring the effectiveness of one couple intervention known as Emotionally Focused Therapy (EFT) for couples that deal with the challenge of ASD. A number of 182 studies were identified as exploring the subject, out of which only four were eligible for further analysis. Two of the studies question the effectiveness of EFT in the case of chronically ill children and the other two question the effectiveness in the case of ASD. The reported results show a decrease of the marital distress following EFT intervention. The review highlights the further need of studies exploring EFT for parents rising ASD children and mentions practical implications of the current analysis.

Keywords: Emotionally Focused Therapy, Autism Spectrum Disorder, couple therapy, family therapy, treatment plan, parents.
\end{abstract}

\section{Introduction}

Autism is one of the most widespread child psychopathologies. Some of the latest statistics suggest that the prevalence of the Autism Spectrum Disorder (ASD) has been constantly growing in recent years (Solomon and Chung, 2012;

${ }^{1}$ Department of Psychology, West University of Timisoara, ROMANIA. E-mail: dalia stoia@yahoo.com

${ }^{2}$ Department of Psychology, West University of Timisoara, ROMANIA. E-mail: mona. vintila@e-uvt.ro

${ }^{3}$ Faculty of Communication and Public Relations, SNSPA Bucharest, ROMANIA. E-mail: mihaelaminulescu@yahoo.com 
Christensen et al., 2018). Also, the understanding of ASD has changed in time according to different versions of DSM. Nevertheless, facing ASD senses facing a variety of chronic symptoms that affect the family functioning and their quality of life (Solomon and Chung, 2012).

Considerable research attention has been given to the impact of ASD on families and although new, innovative methods for improving the functioning of children with ASD are emerging, such as Shadow Theater - an interactive form of storytelling (Mizrachi, Balauta \& Vlaicu, 2018), family difficulties still need to be considered. Children with ASD and their families can often face prejudices and discrimination and even the professionals that are working with them can use an ambigous language that may enhance their social exclusion (Goian, 2012; Goian, 2010; Goian, Vintila, Bucur, 2012). Professionals should always remember that all beneficiaries and their families need counselling that guarantees empathy, respect and authenticity (Goian, 2004). First, in these families, the risk of developing anxious or depressive symptoms is high together with high levels of stress (Lecavalier, Leone, \& Wiltz, 2006; Karst \& Van Hecke, 2012). Attitudes about health and life experiences vary from an individual to another and could be caused by a lack of health information, a low socio-economic level (Vintila et al., 2009), and a lower level of personal development. Although, life experiences are own, subjective experiences they depend not only on the individual, but also on environmental factors that can be more or less controlled (Tudorel, Macsinga, \& Virga, 2013). Thus, social support is an important factor which can be view as a protective factor that could reduce the effect of stressful, overwhelming life events (Tudorel \& Vintila, 2018). In their study, Gau et al. (2012) compared 151 families of children with ASD with 113 families with typically developed children concerning levels of psychopathology. Their results were similar to other findings suggesting a high rate of depressive, anxious and obsessive symptoms, especially among mothers. All of these come together with different couple difficulties (Karst \& Van Hecke, 2012) that lead to a growing rate of divorce among families of ASD children (Hartley et al., 2010; Freedman et al., 2012). An extensive and complete description of facing autism would include: low parental self-efficacy; anxiety related to the child's communication, motor and social skills; stress related to the cognitive difficulties of the child, mood swings of the child, lack of autonomy, hyperactivity, learning difficulties; fatigue; family conflicts; low family functioning; low marriage satisfaction; low quality of life and as mentioned before, high rate of divorce (Karst \& Van Hecke, 2012; Smith et al., 2010; Kelly et al., 2008; Brobst, Clopton and Hendrick, 2009; Gau et al., 2011; Hartley et al., 2011; Higgins, Bailey $\&$ Pearce, 2005). We can, therefore, picture that these families face a complex diagnosis with still debatable ways of treatment (Karst \& Van Hecke, 2012). A complex psychological intervention seems required for such a family situation. However, until recently all the focus was towards the therapy of the child (Karst \& Van Hecke, 2012). It was not until understanding the complex implications of ASD that the perspective changed to highlight the importance of family therapy.

While faced with the new family reality it was suggested that systemic therapy can offer support. Some directions considered for these therapists were helping parents understand and cope with ASD, helping them in taking decisions and facing the grieving of the loss of a possible typically developed child (Bradford, 
2010; Ramisch, 2012; Neely et al., 2012;). Some other recent directions consider more specific treatments such as structural family therapy, double ABCX model, solution-focused brief therapy to ease marital dissatisfaction and parental stress (Smock Jordan and Turns, 2016; Brockman et al.2016). Yet, although it is clear parent's mental health is affected and even more the couple dynamic is altered, evidence regarding the effectiveness of couple therapy is severely lacking. Given the importance of the marital relationship in any family, the need to better know and understand the types of interventions suitable to enhance the partner connection is clear. In a recent pilot study, Lee, Furrow, and Bradley (2017) meant to shed light in the field and analyze the impact of Emotionally Focused Therapy (EFT) in the case of ASD families. More precisely they meant to see if the therapy decreases marital distress and strengthens the couple's relationship. Yet, the effectiveness of EFT for these families is still not fully understood. Considering all of these, the paper aims to review the existing literature referring to EFT in the context of couples rising ASD children. By providing an up to date image of the literature this review intends to meet the above-mentioned gap. It begins by highlighting the main characteristics of ASD and EFT and continues by providing the framework of the review. The next section explores the main findings revealed by the systematic search in the current literature. The paper concludes by reinforcing the importance and the impact of couple connection and by featuring future research directions.

\section{Autism Spectrum Disorder and Emotionally Focused Therapy}

Autism Spectrum Disorder as is currently defined represents a complex of neurological and developmental deficits characterized by a lack of social interaction and communication together with a series of restrictive, repetitive behaviors and stereotypes (APA, 2013). As above mentioned, considerable research attention has been directed towards the etiology of the disorder and on the mental health consequences associated with raising a child with ASD (Lee, Furrow \& Bradley, 2017).

Emotionally Focused Therapy approach has also yielded a substantial body of literature revealing its effectiveness. Developed in 1985 by Johnson and Greenberg, EFT's goal is to diminish the couple levels of stress by developing a secure attachment style between the partners (Lebow et al., 2012). In order to achieve this, the therapy views emotions as a means of change (Johnson, 2004). According to Johnson (2004), the way we process emotions is essential in adapting to reality an in the meaning and sense we give to our life. In other words, the problems occur when emotions are not assumed or denied (Johnson, 2004). Consequently, emotions are considered a path to understanding the fundamental needs of attachment of all humans. In order to achieve its goal, the therapy seeks to help the couple to recognize and accept emotions and to change the way they answer to emotions (Johnson, 2008). The major specific targets are: to explore emotions, to change the interaction between the partners and to create a secure connection between the partners. 


\section{Methods}

A scientific literature search was performed within Ebsco, Proquest, Science Direct, Pubmed database and ultimately in the non-official source of Google Academic. The following research keywords were used in the search strategy Emotionally Focused Therapy, Autism, Autism Spectrum Disorder, Children with Disabilities. The considered eligibility criteria for the articles were: (1) peer-reviewed studies written in English, (2) studies conducted in the last 10 years (2008 - 2018); (3) experimental studies (with a control group like treatment as usual, placebo, waiting list of no treatment), quasi-experimental studies (reporting results for pretest and posttest evaluation) or non-experimental studies; (4) the participants included in the studies were couples raising a child on the spectrum; (5) the intervention used for the couples was EFT.

Throughout the process, there were 4 important steps that were accomplished: identification, screening, eligibility, and inclusion. In the first step, we identified 182 number of possible eligible literature as follows: Ebsco 4 studies, Proquest 0 studies, Science Direct 5 studies, Pubmed 0 studies, studies and Google Academic 173 studies (including duplicates). The search within Google Academic was performed due to the poor number of identified studied throughout the international database. The following phase was to screen the studies and to exclude all the duplicate studies. This meant that from 182 articles, 36 were excluded. Out of the 142 remaining studies, we identified 42 books, 94 non-experimental studies, 2 links leading to journals and 4 experimental studies. All the 4 experimental studies did not meet the proposed criteria. More precisely they explored different topics as follows: attachment theory and engagement (Arthur, 2008), personality and marital satisfaction (Carpenter, 2015), perceptions of infidelity (Stewart, 2017) and EFT impact on happiness. Additionally, one non-experimental study reporting evidence on a connected topic like family therapy for families of children on the spectrum is considered relevant to be mentioned (Callella, 2016). Other non-experimental studies identified as connected to EFT were exploring: the prediction of change in marital satisfaction (Dalgleish et al., 2015), EFT for patients with brain injuries (Edwards et al., 2013), empathy and emotional regulation (Pietrzak, Hauke \& Lohr, 2016). Among all the findings 4 non-experimental research on the topic emerged.

\section{Results}

A total of 4 non-experimental studies were reviewed on the topic of EFT for families of children with ASD. These scientific articles were conducted in 1996 (Walker et al., 1996), in 2002 (Cloutier et al., 2002), in 2013 (Ramisch et al., 2013) and in 2017 (Lee, Furrow and Bradley, 2017). The review presents the following data: study characteristics (Table 1), methodology of identified studies and reported results (Table 2). 


\section{Overview of studies upon EFT for couples raising a child with ASD}

Walker and his colleagues (1996) are the first to be mentioned as reporting a study carried out in order to test the effectiveness of EFT of for families with chronically ill children. In their study, they randomly assigned 32 couples into the experimental group or the waitlist control group. The treatment offered was 10 sessions of EFT of 90 minutes each. Couples were examined on the following dependent variables: marital adjustment, communication, intimacy, and therapy alliance. The reported results showed clinical improvements in marital functioning following EFT including 5 months after the intervention. Subsequently, two years after the therapy ended, Cloutier and his colleagues (2002) carried out a follow-up study aiming to analyze the poorly examined effects of the long-term efficacy of couple therapy interventions and the lack of long term follow up data on EFT. All the couples that participated in the prior mentioned study were invited to participate in the follow-up study. More than eighty percent of the couples agreed to participate. The assessment focused on marital adjustment and intimacy while the new results showed that the effect was not only maintained but enhanced in time.

At this point, the significant results above mentioned adding some light upon the effectiveness of EFT for couples raising a chronically ill child, which draws our attention as ASD is a chronic condition. In recent years, more attention has been directed towards the effectiveness of the therapy of couples that face their child's ASD. Ramisch and his colleagues (2013) conducted a qualitative study in order to distinguish the relevance of EFT therapy for 3 couples of children with ASD. The couples benefit for 10 weeks of one-hour EFT intervention provided in-home. Three licensed therapists were involved in the study and the main description of the used framework includes the therapy sessions, supervision and semi-structured interviews carried out with the couples regarding the relevance of the therapy. For each couple, the authors report arguments concerning the therapist reflections, the supervisor reflections, and a qualitative post-intervention interview. The conclusions of the authors were based on the experience of the three couples and reflected the consideration that the couples would benefit from in-home therapy in order for the relationship to strengthen. Also, the authors highlight some implications for practice like the fact that the therapist should forget any misconception regarding the communication of couples with ASD children and focus to discover the communication pattern of the couple. Furthermore, the authors draw our attention to the fact that more research concerning marital interventions for couples with ASD children is highly needed.

Lee, Furrow and Bradley (2017) conducted a study regarding the effectiveness of EFT and ASD parents considering that EFT showed relevant potential in the case of couples rising chronically ill children and that the parents of ASD children confront great relational distress. Seven couples were included in the study and received 12 weeks of EFT treatment each lasting 75 minutes. The couples were assessed at the beginning of the treatment, posttest and 6 months follow up with respect to marital adjustment, intimacy, attachment strategies trust and commitment. The study concludes by highlighting the benefits of EFT in decreasing marital distress. 
Table 1. Study Characteristics

\begin{tabular}{|c|c|c|c|c|}
\hline Study & N & Design & $\begin{array}{l}\text { Dependent } \\
\text { variable }\end{array}$ & Measurement \\
\hline $\begin{array}{l}\text { Walker et al., } \\
1996\end{array}$ & 32 couples & Experimental & $\begin{array}{l}\text { marital } \\
\text { adjustment, } \\
\text { communication, } \\
\text { intimacy, therapy } \\
\text { alliance }\end{array}$ & $\begin{array}{l}\text { Dyadic adjustment scale } \\
\text { Miller social intimacy } \\
\text { scale, } \\
\text { Communication Skills } \\
\text { Test, } \\
\text { Couples Therapy Alliance } \\
\text { Scale }\end{array}$ \\
\hline $\begin{array}{l}\text { Cloutier et al., } \\
2002\end{array}$ & & $\begin{array}{l}\text { Non- } \\
\text { experimental }\end{array}$ & $\begin{array}{l}\text { marital } \\
\text { adjustment, } \\
\text { intimacy }\end{array}$ & $\begin{array}{l}\text { Dyadic adjustment scale } \\
\text { Miller social intimacy } \\
\text { scale, } \\
\text { Parent Stress Index }\end{array}$ \\
\hline $\begin{array}{l}\text { Ramisch et. al., } \\
2013\end{array}$ & 3 couples & $\begin{array}{l}\text { Non- } \\
\text { experimental } \\
\text { (qualitative) }\end{array}$ & & Semi-structure interview \\
\hline $\begin{array}{l}\text { Lee, Furrow } \\
\text { and Bradley } \\
\text { (2017) }\end{array}$ & 7 couples & $\begin{array}{l}\text { Quasi- } \\
\text { experimental }\end{array}$ & $\begin{array}{l}\text { marital } \\
\text { adjustment, } \\
\text { intimacy, } \\
\text { attachment } \\
\text { strategies, trust } \\
\text { and commitment }\end{array}$ & $\begin{array}{l}\text { Dyadic adjustment scale } \\
\text { Miller social intimacy } \\
\text { scale, } \\
\text { Experience in close } \\
\text { relationships - revised, } \\
\text { Trust scale, } \\
\text { Dedication commitment } \\
\text { subscale }\end{array}$ \\
\hline
\end{tabular}

The present overview shows out that at present the two main bodies of research concern firstly the effectiveness of EFT for couples that face a chronical disease of the child, while the second body focuses one a more particular subject which is the effectiveness of EFT for couples that face the ASD of their child. While the two main strands in the literature seem connected, yet they give us two slightly different answers. Walker and his colleagues (1996) and Cloutier and his colleagues (2002) talk about the effects of EFT upon a wider range of diseases like diabetes, epilepsy, cancer, asthma, spina bifida and so on. The answers that this body of research offers us are of great importance, yet the particularities of facing all the mentioned chronic diseases may be different from the particularities facing the chronicity of ASD. At this point may be considered that the first body shows that in general marital therapy is effective for couples facing chronic physiological conditions and the second body of research comes to examine if the general effectiveness prior mentioned stands for a different type of chronicity, a more psychological condition of the child.

Also, between the two bodies of research, we can see that the used methodology differs. While Walker et al. (1996) followed an experimental design Cloutier et al. (2002) report a non-experimental design according to their research question. On the other hand, within the stand concerning EFT and ASD, Ramisch et. al. (2013) used a qualitative design, while Lee, Furrow and Bradley (2017) a quasi-exper- 
imental design. From this point, we can observe the heterogeneity of only four studies and the total lack of experimental studies concerning EFT and ASD. The common measured dependable variables were marital adjustment, intimacy and communication, while Lee, Furrow and Bradley (2017) added two more variables in attachment strategies and trust. Also, Dyadic adjustment scale and Miller social intimacy scale were two commonly used scales in three studies (Walker et al., 1996; Cloutier et al., 2002; Lee, Furrow and Bradley, 2017).

As far as the results concern, we can observe more of a homogeneity. Although Walker et al. (1996) and Cloutier et al. (2002) focused on slightly different research questions, the reported numbers reveal the effectiveness of EFT. Some of the results reported by Walker et al. (1996) concern a $t$ value of $4.64(\mathrm{p}=.01)$ for posttreatment marital adjustment, $4.67(\mathrm{p}=.01)$ for follow up martial adjustment, $3.33(\mathrm{p}=.01)$ for follow up intimacy and $2.88(\mathrm{p}=.05)$ communication, while Cloutier et al. (2002) report an $F$ value of $17.5(\mathrm{p}=.00)$ for 2 years follow up marital adjustment and no significant effect for 2 years follow up intimacy. In line with this numbers, but again, speaking about different chronicity, Lee, Furrow and Bradley`s (2017) report and $F$ value of $3.15(\mathrm{p}=.07)$ for intimacy and 9.10 $(\mathrm{p}=.01)$ for dyadic adjustment. According to the reports, the pilot study of Lee, Furrow and Bradley (2017) are in line with the findings of the chronic illness studies showing that EFT in the case of ASD proves effective. Yet, bought strands of research highlight the need for further research.

Table 2. Means and Standard deviations for Dyadic Adjustment and Intimacy

\begin{tabular}{|c|c|c|c|c|c|c|c|}
\hline \multirow{2}{*}{ Article } & \multirow{2}{*}{$\begin{array}{l}\text { Dependent } \\
\text { Variable }\end{array}$} & \multicolumn{2}{|c|}{ Pretest } & \multicolumn{2}{|c|}{ Posttest } & \multicolumn{2}{|c|}{ Follow-up } \\
\hline & & $M$ & SD & $M$ & SD & $\mathrm{M}$ & SD \\
\hline $\begin{array}{l}\text { Walker et al., } \\
1996\end{array}$ & \multirow[t]{3}{*}{$\begin{array}{l}\text { Dyadic } \\
\text { Adjustment }\end{array}$} & 99.7 & 8.3 & 109.6 & 9.2 & 108.2 & 7.8 \\
\hline $\begin{array}{l}\text { Cloutier et al., } \\
2002\end{array}$ & & - & - & - & - & 108.31 & 13.17 \\
\hline $\begin{array}{l}\text { Lee, Furrow and } \\
\text { Bradley (2017) }\end{array}$ & & 100.00 & 8.76 & 110.29 & 7.43 & 111.43 & 5.97 \\
\hline $\begin{array}{l}\text { Walker et al., } \\
1996\end{array}$ & \multirow[t]{3}{*}{ Intimacy } & 127.7 & 12.5 & 138.5 & 12.4 & 138.5 & 16.5 \\
\hline $\begin{array}{l}\text { Cloutier et al., } \\
2002\end{array}$ & & - & - & - & - & 133.46 & 16.96 \\
\hline $\begin{array}{l}\text { Lee, Furrow and } \\
\text { Bradley (2017) }\end{array}$ & & 131.43 & 15.04 & 138.00 & 7.30 & 136.29 & 17.42 \\
\hline
\end{tabular}




\section{Discussion}

Autism Spectrum Disorder (ASD) is still on the rise according to recent surveys. The impact of the diagnosis increases the marital distress of the couple facing the ASD challenge. Maybe the severest consequence of the named impact is the high rate of divorce among couples of children with ASD. However, it was not until recently that the importance of a multifaced treatment plan was highlighted. In this context, the effectiveness of couple interventions is still not fully known. The goal of the present literature review was to identify the existing literature referring to EFT which is known as a specific short-term couple intervention.

A scientific literature search was performed, and 182 studies were at first identified. After a more detailed process of screening, only 4 studies were identified as exploring the effectiveness of EFT in the case of couples raising a child on the spectrum. Walker and his colleagues (1996) were the first identified in the present literature review as concluding that EFT intervention is effective for families with chronically ill children. As two years follow up, Cloutier and his colleagues (2002) concluded that the outcomes of the intervention resisted in time. Subsequently, Ramisch and his colleagues (2013) in a qualitative study considered that in-home EFT was effective for 3 couples of children with ASD. Lastly but not least, Lee, Furrow and Bradley (2017) presented the results of their study which indicated the effectiveness of EFT for seven couples of children with ASD in decreasing marital distress. The analysis of the studies revealed two connected bodies of research. Firstly, research focused on investigating the effectiveness of EFT in the cases of couples rising chronically ill children and secondly research investigated the effectiveness of the intervention in the case of ASD. Although ASD is also a chronic condition same as the physiological chronic conditions included in the first body of research, the effectiveness of EFT is far more precisely analyzed in the second body of research which included only families facing ASD. The general conclusion of the first body of research was confirmed by Ramisch et al. (2013) and Lee, Furrow and Bradley (2017). Overall, these findings support an underprivileged body of research. Consequently, future research would benefit from more studies analyzing the effectiveness of couple interventions in the case of parents that face ASD.

\section{Conclusion}

The first issue to be noted as mentioned before is that the literature regarding EFT and couples raising a child on the spectrum is currently insufficient. Through the review, we were able to identify that only in the last six year the interest was drawn towards the effectiveness of the intervention in the case of ASD. Some possible practical approaches emerge from the review: (1) Psychological interventions for families of children on the spectrum are essential; (2) Couples benefit from interventions targeting a decrease in marital distress. Organizations and institutions that offer therapy programs for ASD could consider offering short programs focusing on the marital relationship and 
monitor the effectiveness; (3) ASD's impact on families is well known and the importance of a multifaced treatment plan is obvious. Organizations and institutions that offer therapy programs for ASD could consider adapting their services to the value of this conclusion; (4) All specialist in mental health could consider talking about and validate all the struggle of a family facing the ASD challenge. Recommendations for couple therapy could be also considered.

Taken together the present review reinforces that literature still lacks fully knowing the effectiveness of EFT for couples that face ASD and that the importance of the topic is of value for theoretical and practical approaches. The main limitation of the current literature review should be acknowledged as the insufficient studies included supporting the prior conclusions.

\section{References}

American Psychiatric Association. (2013). American Psychiatric Association. DSM-5. APA DSM, 5.

Arthur, K.B. (2008). Attachment styles and Enneagram types: Development and testing of an integrated typology for use in marriage and family therapy (Doctoral dissertation, Virginia Tech).

Brobst, J.B., Clopton, J. R., \& Hendrick, S.S. (2009). Parenting children with autism spectrum disorders: The couple's relationship. Focus on Autism and Other Developmental Disabilities, 24(1), 38-49.

Brockman, M., Hussain, K., Sanchez, B., \& Turns, B. (2016). Managing child behavior problems in children with autism spectrum disorders: Utilizing structural and solution focused therapy with primary caregivers. The American Journal of Family Therapy, 44(1), 1-10.

Callella, N.D. (2016). Incorporating family systems interventions for children with autism and their families (Doctoral dissertation, Alliant International University).

Carpenter, D.G. (2015). Resonating Personality Types for Couples: An Enneagram Application for Predicting Marital Satisfaction.

Christensen, D.L., Braun, K.V.N., Baio, J., Bilder, D., Charles, J., Constantino, J. N., ... \& Lee, L. C. (2018). Prevalence and characteristics of autism spectrum disorder among children aged 8 years -autism and developmental disabilities monitoring network, 11 sites, United States, 2012. MMWR Surveillance Summaries, 65(13), 1.

Cloutier, P.F., Manion, I.G., Walker, J. G., \& Johnson, S. M. (2002). Emotionally focused interventions for couples with chronically ill children: A 2-year follow-up. Journal of marital and family therapy, 28(4), 391-398.

Dalgleish, T. L., Johnson, S. M., Burgess Moser, M., Lafontaine, M. F., Wiebe, S. A., \& Tasca, G. A. (2015). Predicting change in marital satisfaction throughout emotionally focused couple therapy. Journal of marital and family therapy, 41(3), 276-291.

Edwards, A., Murray, C., Creamer, N., Mahadevan, M., \& Yeates, G. (2013). The use of emotionally-focused couples therapy (EFT) for survivors of acquired brain injury with social cognition and executive functioning impairments, and their partners: a case series analysis. Neuro-Disability and Psychotherapy, 1(2), 151-197.

Freedman, B. H., Kalb, L. G., Zablotsky, B., \& Stuart, E. A. (2012). Relationship status 
among parents of children with autism spectrum disorders: A population-based study. Journal of Autism and Developmental Disorders, 42(4), 539-548.

Gau, S. S. F., Chou, M. C., Chiang, H. L., Lee, J. C., Wong, C. C., Chou, W. J., \& Wu, Y. Y. (2012). Parental adjustment, marital relationship, and family function in families of children with autism. Research in Autism Spectrum Disorders, 6(1), 263-270.

Goian, C. (2004). Deprinderi în asistența sociala. Iasi: Institutul European.

Goian, C. (2012). Semantic analysis of the dynamics of the social work language applied in Romania. București: Pro Universitaria.

Goian, C. (editor) (2013). Teaching social work practice. Bucureşti: Pro Universitaria

Goian, C., Vintila, M., \& Bucur, V. M. (2012). Analysis of terminology usage for Romapeople among Social Work professionals in Romania. Social Research Reports, 22, 5-27

Hartley, S.L., Barker, E.T., Seltzer, M.M., Floyd, F., Greenberg, J., Orsmond, G., \& Bolt, D. (2010). The relative risk and timing of divorce in families of children with an autism spectrum disorder. Journal of Family Psychology, 24(4), 449.

Hartley, S.L., Barker, E.T., Seltzer, M.M., Greenberg, J.S., \& Floyd, F.J. (2011). Marital satisfaction and parenting experiences of mothers and fathers of adolescents and adults with autism. American Journal of Intellectual and Developmental Disabilities, 116(1), 81-95.

Higgins, D. J., Bailey, S. R., \& Pearce, J. C. (2005). Factors associated with functioning style and coping strategies of families with a child with an autism spectrum disorder. Autism, 9(2), 125-137.

Johnson, S. (2008). Hold me tight: Seven conversations for a lifetime of love. Hachette UK. Johnson, S.M. (2004). Creating connection: The practice of emotionally focused couple therapy. New York: Brunner-Routledge.

Johnson, S.M., \& Greenberg, L. S. (1985). Differential effects of experiential and problem-solving interventions in resolving marital conflict. Journal of Consulting and Clinical Psychology, 53(2), 175.

Karst, J.S., \& Van Hecke, A.V. (2012). Parent and family impact of autism spectrum disorders: A review and proposed model for intervention evaluation. Clinical Child and Family Psychology Review, 15(3), 247-277.

Kelly, A. B., Garnett, M. S., Attwood, T., \& Peterson, C. (2008). Autism spectrum symptomatology in children: The impact of family and peer relationships. Journal of Abnormal Child Psychology, 36(7), 1069.

Lebow, J. L., Chambers, A. L., Christensen, A., \& Johnson, S. M. (2012). Research on the treatment of couple distress. Journal of Marital and Family therapy, 38(1), 145-168

Lecavalier, L., Leone, S., \& Wiltz, J. (2006). The impact of behaviour problems on caregiver stress in young people with autism spectrum disorders. Journal of Intellectual Disability Research, 50(3), 172-183.

Lee, N.A., Furrow, J. L., \& Bradley, B. A. (2017). Emotionally focused couple therapy for parents raising a child with an autism spectrum disorder: A pilot study. Journal of Marital and Family Therapy, 43(4), 662-673.

Mizrachi, H., Balauta, D. S., \& Vlaicu, F. L. (2018). An innovative teaching method to improve the functioning of children with Autism Spectrum Disorder: a comparative analysis between storytelling and shadow theater. Social Research Reports, 10(1), 51-63.

Neely, J., Amatea, E.S., Echevarria-Doan, S., \& Tannen, T. (2012). Working with families living with autism: Potential contributions of marriage and family therapists. 
Journal of Marital and Family Therapy, 38, 211-226.

Pietrzak, T., Hauke, G., \& Lohr, C. (2016). Connecting Couples Intervention: Improving couples' empathy and emotional regulation using embodied empathy mechanisms. Eur. Psychother, 13, 66-98.

Ramisch, J. (2012). Marriage and family therapists working with couples who have children with autism. Journal of Marital and Family Therapy, 38(2), 305-316.

Ramisch, J.L., Timm, T.M., Hock, R.M., \& Topor, J.A. (2013). Experiences delivering a marital intervention for couples with children with autism spectrum disorder. The American Journal of Family Therapy, 41(5), 376-388.

Smith, I.M., Koegel, R.L., Koegel, L.K., Openden, D.A., Fossum, K.L., \& Bryson, S.E. (2010). Effectiveness of a novel community-based early intervention model for children with autistic spectrum disorder. American Journal on Intellectual and Developmental Disabilities, 115(6), 504-523.

Smock Jordan, S., \& Turns, B. (2016). Utilizing solution-focused brief therapy with families living with autism spectrum disorder. Journal of Family Psychotherapy, 27(3), 155-170.

Solomon, A.H., \& Chung, B. (2012). Understanding autism: How family therapists can support parents of children with autism spectrum disorders. Family Process, 51(2), 250-264.

Stewart, C. M. (2017). Attitudes, Attachment Styles, and Gender: Implications on Perceptions of Infidelity. https://digitalscholarship.unlv.edu/cgi/viewcontent.cgi?article $=4175 \&$ context $=$ thesesdissertations

Tudorel, O. I., Macsinga, I., Virga, D. (2013). Actualizarea de sine: de la starea de bine la viziunea asupra lumii. Romanian Journal of Applied Psychology, 15 (1), 20-26;

Tudorel, O. I., Vintila, M. (2018). The role of Social Support on Internet Addiction. Revista de Asistenta Sociala, 1 ;

Vintila, M., Marklinder, I., Nydahl, M., Istrat, D., \& Kuglis, A. (2009). Health awareness and behaviour of the elderly: between needs and reality. A comparative study. Revista de Psihologie Aplicata, 11(2), 81-87;

Walker, J. G., Johnson, S., Manion, I., \& Cloutier, P. (1996). Emotionally focused marital intervention for couples with chronically ill children. Journal of Consulting and Clinical Psychology, 64(5), 1029. 